\title{
Effects of Ammonia/HTT Compound Preservative on the Preservation and Properties of Concentrated Natural Rubber Latex
}

\author{
Weiqiang $\mathrm{Yu}^{1,2, \mathrm{a}}$, Hongxing Gui ${ }^{2, \mathrm{~b}}$, Ting Wang ${ }^{2, \mathrm{c}}$, Jianlong Wang ${ }^{1, \mathrm{~d}}$, Rizhong \\ Zeng $^{3, e}$, Maofang Huang ${ }^{2, f}$
}

\author{
${ }^{1}$ College of Chemical Engineering and Environment of North University of China, Taiyuan 030051, \\ Shanxi, China \\ ${ }^{2}$ Agricultural Product Processing Research Institute, Chinese Academy of Tropical Agricultural \\ Science, Zhanjiang 524001, Guangdong, China \\ ${ }^{3}$ Rubber Research Institute, Chinese Academy of Tropical Agricultural Science, Danzhou 571737, \\ Hainan, China \\ a0716ywq@sina.com, bguihongxing@263.net, 'c379196654@qq.com, dwangjianlong@nuc.edu.cn, e \\ hnzrz@yahoo.com.cn, 'thmf126520@163.com
}

Keywords: Concentrated natural rubber latex; Composited preservative; Films; Mechanical properties

\begin{abstract}
Ammonia and HTT were compounded and tested as a novel preservative system for concentrated natural rubber latex (CNRL) to replace traditional preservatives. The preservation effects and the viscosity of prevulcanized CNRL were measured. After preservation treatment, the drying characteristics, the mechanical properties and IR of vulcanized natural rubber latex films were evaluated. It was found that $0.4 \% \mathrm{w} / \mathrm{w}$ ammonia and $0.1 \% \mathrm{w} / \mathrm{w}$ HTT allowed the preservation of CNRL for more than 180 days. The volatile fatty acid number (VFA NO.) and mechanical stability test (MST) of the preserved materials met the ISO 2004:2010(E) standard. In addition, the viscosity of prevulcanized CNRL exhibited little change. The drying time of vulcanized NRL film was relatively short which indicated that the drying efficiency of products were higher. The tensile strength and tear strength reached $34.81 \mathrm{MPa}$ and $46.43 \mathrm{kN} / \mathrm{m}$ respectively, higher than that achieved using the traditional method of preservation. Additionally, the results of IR showed that ammonia/HTT compound preservative did not change the constitution of vulcanized NRL film.
\end{abstract}

\section{Introduction}

After removal from the tree, natural rubber latex (NRL) becomes contaminated easily, due to microorganism growth and acid production, so appropriate preservatives must be added to maintain its stability and purity. Ammonia with tetramethylthiuram disulfide (TMTD) and zinc oxide (ZnO) are widely used for the preservation of NRL and CNRL. However, the frequent use of the plant growth regulator ethephon in rubber cultivation increased the amount of non-rubber components in NRL, making it a challenge to achieve adequate preservation using the traditional preserved system. The traditional preserved system also has negative environmental consequences due to air pollution effects caused by the ammonia and the production of carcinogenic nitrosamine substances resulting from TMTD[1]. The growing awareness of the need for environmental protection increases the urgency for the research and development of new preservatives to replace the existing system.

In recent years, much works had been done to research efficient non-ammonia preservatives[2]. HTT (a derivative of sym-triazine), an efficient preservative, is widely used in many fields of industry because it is eco-friendly and harmless to humans. HTT preserved CNRL as a non-ammonia preservative efficiently and increased the mechanical properties of NRL films 
compared to those produced by traditional preservatives[3]. In this study, HTT was used to compound with ammonia to preserve CNRL in a low-cost process. VFA NO. and MST of preserved materials were tested to determine the degree of preservation, and the viscosity of prevulcanized CNRL, film-related properties, drying properties, mechanical properties and IR were tested to determine the effects of the compound preservative. This research presents a foundation for the widespread application of HTT in the rubber industry.

\section{Experiment}

\subsection{Materials}

Field NRL latex and the mixture of TMTD and ZnO were provided by Gaozhou Rubber Processing Center (Maoming, China). Other reagents were analytical grade and were used as received.

\subsection{Preparation of Samples}

\subsubsection{Preparation of the CNRL Samples}

Field natural rubber latex was preserved by $0.15 \%$ w/w HTT, CNRL was obtained after centrifugation. A certain amount of ammonia and HTT were added supplementally, according to Table 1, to obtain the CNRL samples. At the same time, high-ammonia sample (HA) and low-ammonia with TMTD/ZnO (LA-TZ, 0.2\% w/w ammonia and 0.013\% w/w TMTD/ZnO) were obtained as control samples.

Table 1 Formulation of the $\mathrm{NH}_{3} / \mathrm{HTT}$ Preserved CNRL Formulation for the Samples

\begin{tabular}{ccc}
\hline Sample & Ammonia $(\% \mathrm{w} / \mathrm{w})$ & HTT $(\% \mathrm{w} / \mathrm{w})$ \\
\hline 1 & 0.2 & 0.1 \\
2 & 0.2 & 0.2 \\
3 & 0.2 & 0.3 \\
4 & 0.3 & 0.1 \\
5 & 0.3 & 0.2 \\
6 & 0.3 & 0.3 \\
7 & 0.4 & 0.1 \\
8 & 0.4 & 0.2 \\
9 & 0.4 & 0.3 \\
\hline
\end{tabular}

\subsubsection{Preparation of the Prevulcanized CNRL}

With heating of constant temperature water bath, the CNRL reached $40^{\circ} \mathrm{C}$, then these ingredients were mixed with CNRL as following formulation (w/w): CNRL, 100; ZDC, 0.5; ZnO, 0.4 ; peregal-O, $0.1 ; \mathrm{KOH}, 0.1$; sulfur, 1.0. Finally, agitation was required for $2 \mathrm{~h}$ at $60^{\circ} \mathrm{C}$, and prevulcanized CNRL was obtained.

\subsubsection{Preparation of the Vulcanized NRL Film}

After 2 days' holding treatment, a specified volume of filterable prevulcanized CNRL was decanted into a glass plane and dried at $25^{\circ} \mathrm{C}$. When the film was thoroughly see-through, leached it for $24 \mathrm{~h}$ in soft water, then vulcanized NRL film was got.

\subsection{Characterization}

\subsubsection{Tests for CNRL and Prevulcanized CNRL}

During the storage time of CNRL, VFA NO. and MST should be tested every 30 days in accordance with GB/T 8292-2008 and GB8301-2008, respectively. The viscosity of prevulcanized CNRL filtrated was examined every $24 \mathrm{~h}$ in 5 days with a viscometer (Brookfield viscometer, USA). 


\subsubsection{Drying Tests of NRL Film}

A specified volume of prevulcanized CNRL was poured onto a class plane and dried at $25^{\circ} \mathrm{C}$ to make $1 \mathrm{~mm}$ film. The film was leached in soft water for $24 \mathrm{~h}$ and dried at $80^{\circ} \mathrm{C}$ with a drier $(841 \mathrm{Y}-2$ thermostatic blast drying oven) until it had a constant weight. During this period, the film was weighed regularly.

\subsubsection{Mechanical Properties}

An electronic tensile testing machine (UT-2080, U-CAN, Taiwan) was adopted to determine the tensile properties and tear strength of the vulcanized NRL films, the two tests were carried out according to GB/T 528-2009 and GB/T 529-2009, respectively.

\subsubsection{FTIR Spectroscopy Analysis}

The IR absorption spectrum of the vulcanized film was tested with a Fourier Transform IR Spectrometer (Spectrum GXI, PerkinElmer, USA). The detection area ranged from 4000 to 500 $\mathrm{cm}^{-1}$, the resolution and test times were set to $4 \mathrm{~cm}^{-1}$ and 16 times, respectively.

\section{Results and Discussion}

\subsection{Effect of Ammonia/HTT Compound Preservative on CNRL Preservation}

As sugar, protein, and other nutrients are consumed by bacteria, volatile fatty acids (VFA) are produced which contribute to a gradual decline of latex stability. Since putrefaction happened between sample 1 to sample 5 in 180 days, sample 6 to sample 9 , HA and LA-TZ were chosen for further analysis. As shown in Fig. 1, the VFA NO. of each sample increased during the preservation process. After 180 days, the VFA NO. of the samples with added ammonia/HTT were below 0.04, and lower than the requirements of ISO 2004:2010(E). From Fig. 1, we could see that samples 7 and 9 had lower VFA than the traditional preservation samples.

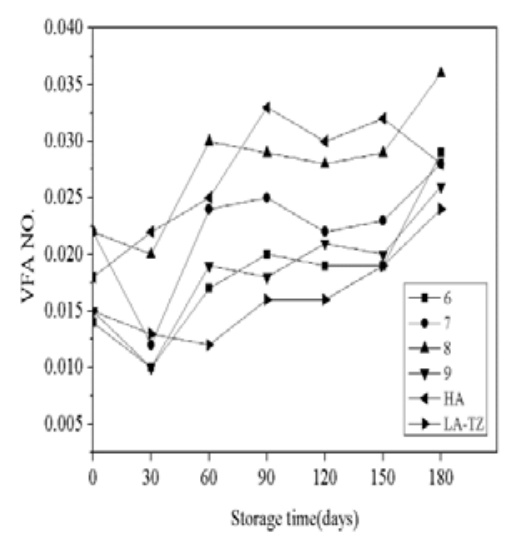

Fig. 1 VFA NO. of CNRL with the storage time

The MST is closely related to the stability of CNRL and the degree of putrefaction can be detected discontinuously. In Fig. 2, the MST of each sample grew moderately in 120 days, then decreased gradually or stabilized. After 180 days, the MST of all samples preserved by ammonia/HTT compound preservative were greater than those preserved by traditional preservatives; sample 7 was 1059 s without the addition of ammonium laurate at 120 days. These effects were caused by the alkaline environment due to the ammonia and HTT which accelerated the promotion of mechanical stability. 


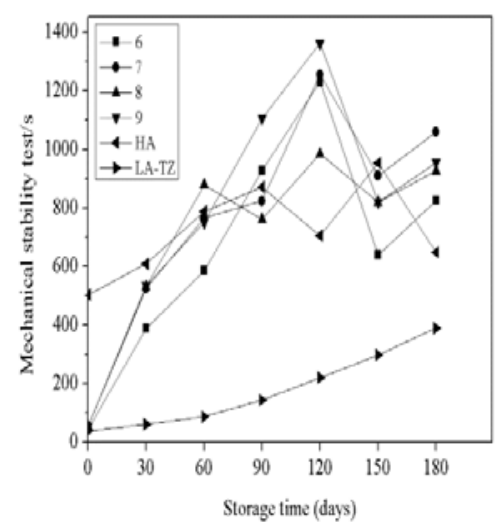

Fig. 2 MST of CNRL with the storage time

The VFA NO. and MST of sample 7 met the national standards and was most economical compared with the other samples. Therefore, sample 7, HA and LA-TZ were chosen for further study.

\subsection{Effect on Viscosity of Prevulcanized CNRL}

Constant viscosity of prevulcanized CNRL is very important because different viscosities can result in inconsistent products. Fig. 3 shows that the viscosity of each prevulcanized CNRL remained unchanged for 5 days except for the sample treated with LA-TZ. This indicated that HTT did not affect the viscosity of prevulcanized CNRL.

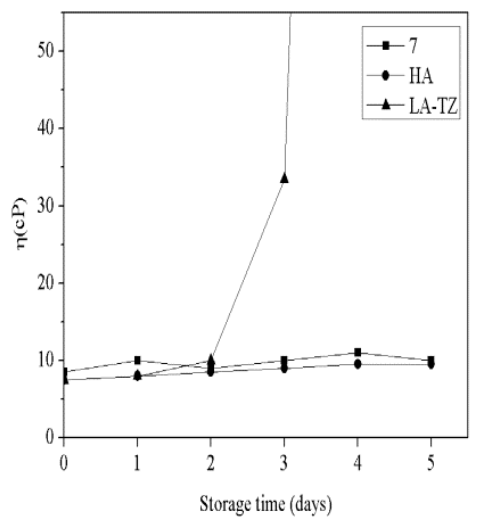

Fig 3. Viscosity of prevulcanized CNRL with the storage time

\subsection{Drying Characteristics of the Vulcanized NRL Film}

Since drying characteristics of films are closely connected with the drying process of latex products, it is important to determine the effects of compound preservative on the drying characteristics of films[4]. As shown in Fig. 4, HA and LA-TZ behaved similarly in that the moisture ratio $\left(\mathrm{M}_{\mathrm{R}}\right.$, as shown in Eq. 1$)$ dropped with increased drying time. In this equation, $x$ is the ratio between the mass of water and solid at a particular time during the process; $x_{e}$ is the ratio between the mass of water and solid at equilibrium condition; $x_{0}$ is the initial ratio between the mass of water and solid. We found that films prepared by ammonia/HTT compound preservative dried in 425 minutes, suggesting that use of ammonia/HTT could improve the drying characteristics of the vulcanized films and increase drying efficiency. 


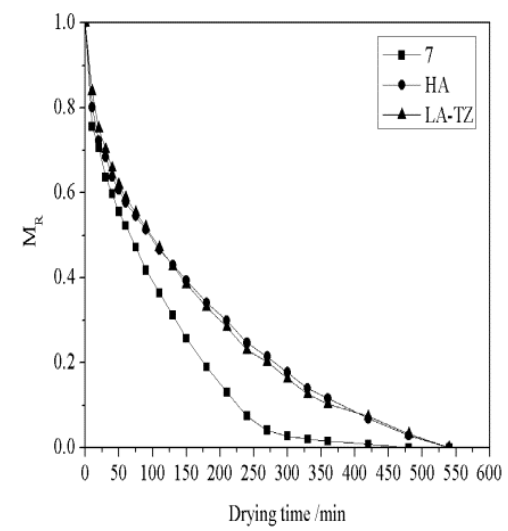

Figure 4. Drying curves of the vulcanized NRL film

$$
M_{R}=\frac{x-x_{e}}{x_{0}-x_{e}}
$$

Eq.1 Definition of the moisture ratio

\subsection{Mechanical Properties of the Vulcanized NRL Film}

Table 2 shows the mechanical properties of the vulcanized NRL films. We found that the tensile strength and tear strength of sample 7 were $34.81 \mathrm{MPa}$ and $46.43 \mathrm{kN} / \mathrm{m}$, respectively. Compared with HA and LA-TZ, there were improvements in the mechanical properties of films prepared by CNRL and ammonia/HTT. This may be because HTT may participate in the crosslinking process, causing an increase of mass of the polysulfided bonds in the net[5].

Table 2. Mechanical Properties of the Vulcanized NRL Film

\begin{tabular}{cccc}
\hline Sample & 7 & HA & LA-TZ \\
\hline Tensile strength $(\mathrm{MPa})$ & 34.81 & 32.7 & 32.3 \\
Elongation at break (\%) & 810.35 & 871.6 & 826.27 \\
300\% modulus (MPa) & 1.55 & 1.24 & 1.29 \\
500\% modulus (MPa) & 4.53 & 3.13 & 3.20 \\
Tear strength $(\mathrm{kN} / \mathrm{m})$ & 46.43 & 44.66 & 35.54 \\
\hline
\end{tabular}

\subsection{IR Analysis of the Vulcanized NRL Film}

FTIR spectra of vulcanized NRL films were performed as shown in Fig. 5. The positions of the characteristic peaks were similar for all samples. This indicated that the compound preservative did not change the constitution of vulcanized NRL films or adversely affect the treated CNRL. 


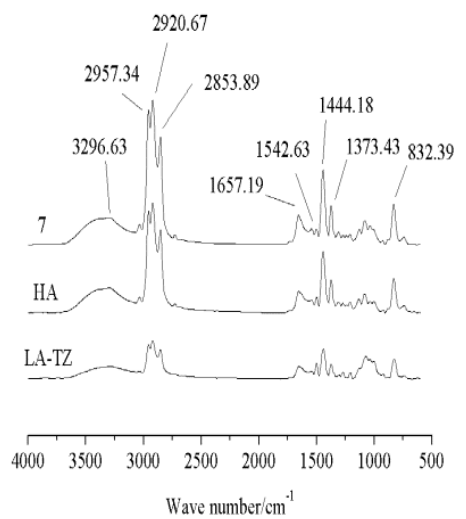

Figure 5. IR Spectral of the Vulcanized NRL Film

\section{Conclusion}

In general, CNRL was preserved more efficiently by the ammonia/HTT compound preservative $(0.4 \% \mathrm{w} / \mathrm{w}$ ammonia and $0.1 \% \mathrm{w} / \mathrm{w}$ HTT) compared with traditional preservatives. The VFA NO. was below 0.03 throughout the process and the MST met the standard after two months. The viscosity of prevulcanized CNRL was not affected. The drying and mechanical properties of vulcanized NRL film treated with this formula were all improved without changing the constitution of the film. Because the mechanism of how ammonia functions with HTT is still unclear, further studies will be needed in the future.

\section{Reference}

[1] Kabara J J, Lopez J, Robert C F. Eliminating nitrosamines in natural rubber latex products. Newsletter of the Rubber-Stichting Information Center for Natural Rubber, Vol. 1(2006), p. 1-4.

[2] Loykulnant S, Kongkaew C, Chaikumpollert O, et al. Study of chitosan and its derivatives as preservatives for field natural rubber latex. Journal of Applied Polymer Science, Vol. 123(2012), p. 913-921.

[3] Ting Wang, Hong-Xing Gui, Wen-Fei Zhang, et al. Novel Non-ammonia Preservative for Concentrated Natural Rubber Latex[J]. Journals of Applied Polymer Science, Vol. 41749(2015), p. 1-6.

[4] Jing C, Lei Y, Jieping Z, et al. Drying kinetics and cross-linking of sulfur prevulcanized thick natural rubber latex film. Rubber Chemistry and Technology, Vol. 86(2013), p. 57-67.

[5] Cheng Wei, Sun Sheying. Research Progress in Characterization of Crosslink Structure of Rubbers. Development and Application of Materials, Vol. 22(2007), p. 48-51. 